\title{
Technology of the discator strip seeding. Condition, prospects
}

\author{
Ivan Ignatenko ${ }^{1}$, Dmitry Melnikov ${ }^{2}$, Yuri Tsarev ${ }^{1, *}$, Sergei Kambulov ${ }^{1,3}$, Viktor Rykov ${ }^{1,4}$, \\ Viktor Khlystunov ${ }^{1,3}$, and Elena Zubrilina ${ }^{1}$ \\ ${ }^{1}$ Don State Technical University, 1 Gagarin Square, Rostov-on-Don, 344003, Russia \\ ${ }^{2}$ Absheron Mechanical Plant (AMZ), st. Koroleva, 122, Apsheronsk, Krasnodar Territory, 352690, \\ Russia \\ ${ }^{3}$ Agricultural Research Centre Donskoy, Lenina st., 14, Zernograd, Rostov Region, 347740, Russia \\ ${ }^{4}$ North Caucasus Institute of Mechanization and Electrification of Agriculture, Zernograd, Russia
}

\begin{abstract}
The article is devoted to the implementation of strip sowing technology with a discator working body. The strip sowing, in comparison with the existing row sowing, increases the area of seed feeding, which increases the yield of grain crops. The coulters currently used for strip sowing with the under-spreading distributor are energy intensive and prone to clogging. It is proposed to use disc spherical disc coulters with a distributor. Compact designs of disc seed drills with spherical disc openers have been developed, which can replace bulky seeding complexes. Disc seed drills combine strip sowing with mini and no-till, reducing energy consumption, increasing speeds and productivity. Providing seeds with nutritional areas of at least $10 \mathrm{~cm} 2$, they actually implement a new technology for sowing cereals, which can increase yields by 2-3 times compared to ordinary sowing.
\end{abstract}

\section{Introduction}

Increasing the yield of grain crops does not lose its relevance throughout the post-war decades. The search continues for resources to increase it while reducing costs. Analysis of technologies for cultivation of grain crops shows that sowing technologies have a significant potential for increasing yields. They are characterized primarily by the sowing method, which determines the topology of seed placement in the field area.

In modern grain production, ordinary sowing is usually used, which came to the fields of Russia from Europe over 100 years ago. In Russia, it is carried out mostly with two-disc coulters (Figure 1, a), stably working on rough agricultural backgrounds. Row spacing bM of the row sowing of cereals (uwsually $\mathrm{bM}=15 \mathrm{sm}$ ) developed historically and is not substantiated either by experience or by the science of agricultural production $[1,16]$. The seeds are arranged in rows (lines), in the rows the seeds are arranged chaotically, the distance ai between them is random.

Sowing equipment is also being developed for drill sowing. About $90 \%$ of all grain seeders in Russia are seed drills (mechanical, pneumatic). Agrotechnical requirements have

\footnotetext{
*Corresponding author : ycarev@donstu.ru
} 
also been developed for drill sowing, which establish strict standards for sowing indicators: (seeding depth and its uniformity; loosening, crumbling of the over-seed layer, density of the furrow bottom, etc.). But such an important factor in productivity as ensuring the area of plant nutrition is not given due attention.

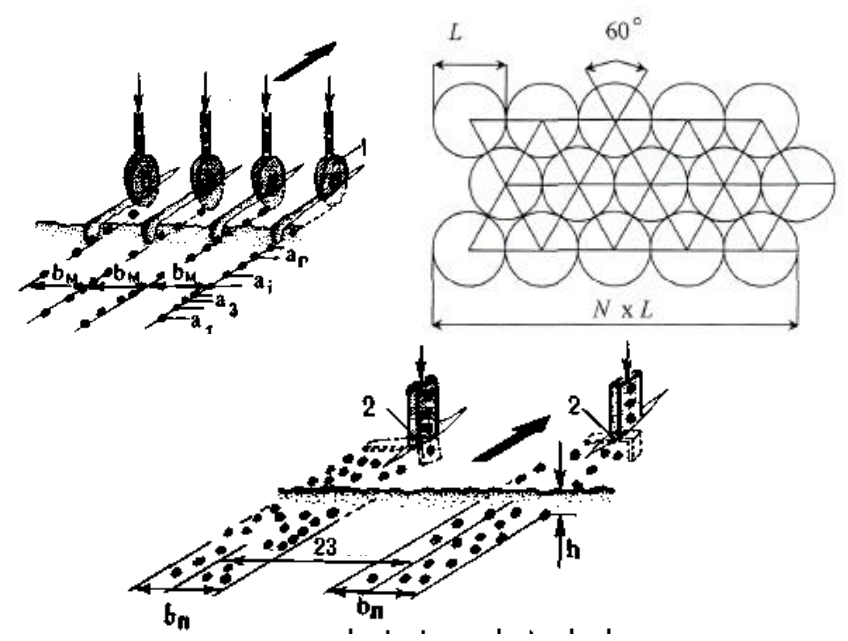

Fig. 1. Sowing methods of grain crops: $a$ - seed drill with double disc coulters; $b$ - stripe: 1 - coulter; 2 - coulter paw; al ......an - distance between seeds in rows; bM - row spacing; bn - width of stripes; $\mathrm{h}-$ sowing depth.

\section{Materials and methods}

Studies show that the optimal feeding area of one grain plant, depending on soil and climatic conditions, should be $10 \ldots 30 \mathrm{~cm}^{2}$ [Bakhmutov V.A., Kirov A.A., Sinyagin I.I.], and in shape it approaches a circle. The topology of the row sowing of grain crops with such areas of nutrition does not provide seeds; areas overlap, thickening of plants appears in the rows, because of empty row spacings, the field area is not fully used. Cultivated plants can only use about $20 \%$ of the field area (the rest is provided by weeds). All this reduces the yield.

The most complete use of the field area will be achieved with ideally distributed sowing, when the grain feeding areas are evenly distributed over the field surface without overlapping, for example, with triangulation placement (Figure 1, b). However, its implementation meets technical difficulties.

The strip sowing method is the closest to the ideal seed distribution (Figure 1, c). But it also has technical problems, one of which is the design of the opener. Currently, for strip sowing, a number of designs of paw openers are proposed (Figure 2, a), in which a distributor of various shapes is installed under the paw, breaking the stream of seeds on the sides and creating an imitation of spread [Tyskineev D.O., Garmaev Ts.I., Mungalov V.A. Alekseev V.P., Buchma A.V., Nuikin A.A. and etc.]. However, the outlet slots of the spreader are prone to clogging, especially on waterlogged soils. In addition, the tine coulter has an increased traction resistance. 


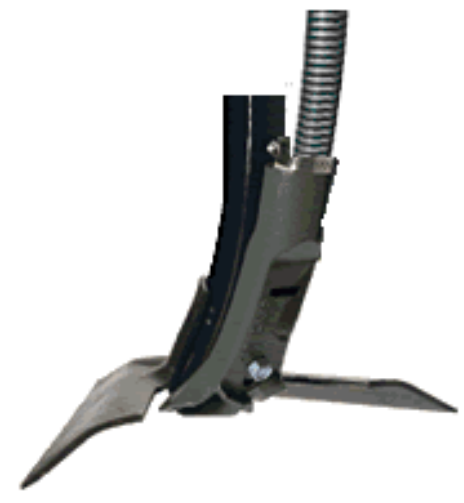

a

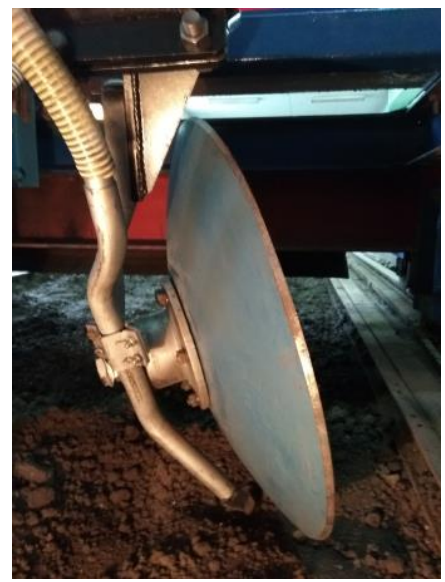

b

Fig. 2. Cereal strip sowing coulters: $a$ - paw coulter Salford; $b$ - innovative spherical disc coulter.

Disc coulters are more resistant to clogging. They are used for both row and strip seeding. So in grain seed drills, a typical double-disc opener is used (Figure 1, a). It has a small sowing width of $10 \ldots 12 \mathrm{~mm}$.

For strip sowing, they are trying to use single-disc openers of different shapes: flat, conical and recently spherical discs (spherical discs) of large diameters $(660 \ldots 750 \mathrm{~mm})$ [Atnagulov D.T., Eruslanov A.K., Kurushin, V.V., Melnikov D.G. and etc.]. Furrowing has become a problematic issue here.

Kurushin V.V. [3-5, 16] applied them in a pneumatic seeder with a V-shaped frame; coulter with spherical vertical disc. Small angle of attack of the spherical disc coulter $\alpha=10^{\circ}$ makes the furrow narrow. This seeder can only carry out seed drilling.

Atnagulov D.T. [6-7] offered a single-disc conical opener with a bed former and a diffuser (Figure 2, d). With a row spacing of $75 \ldots 85 \mathrm{~mm}$, the seeding band of seeds was $50 \ldots 63 \mathrm{~mm}$. In comparison with the double-disc coulters of the SZ-3.6 serial seeder, the number of plants provided with the calculated feeding area increases to $45 \%$ versus $15 \%$ in the control.

Eruslanov A.K. used large-diameter spherical discs for sowing and created a whole family of cultivating seeders: "Guamka"; "Merlin"; "MP-3"; "Sterkh"; "MinSemLab"; "Vorskla"; seeder "Eruslanov-Zolotovsky" and the so-called plant substitutes R-1.8, R-4.2, R-6.8. [1, 68]. Strip sowing was not provided, the sowing strip width is not mentioned in the technical specifications. But experimentally the strip width was estimated to be about $80 \mathrm{~mm}$.

To study the issues of expanding the sowing strip with spherical disc coulters, studies were carried out. It was found that a spherodisk, installed at an angle of attack $\alpha$ and an angle of inclination $\beta$ (Figure 3), performs furrowing by its frontal surface, the shape of which is an inclined ellipse.

An analytical model of the spherodisk groove profile in a universal dimensionless form is obtained:

$$
v=\cos \alpha \sin \beta \frac{\eta}{\cos \beta} \pm \frac{\sin \alpha}{\cos \beta} \sqrt{2 \eta \cos \beta-\eta^{2}},
$$

where $v=\frac{y_{b}}{R}$ and $\eta=\frac{z_{b}}{R}-$ dimensionless furrow shape indicators; $\mathrm{yb}$ - current furrow width at the depth of $\mathrm{zb}$.

The furrow profile is asymmetrical and far from rectangular (Figure 3). 


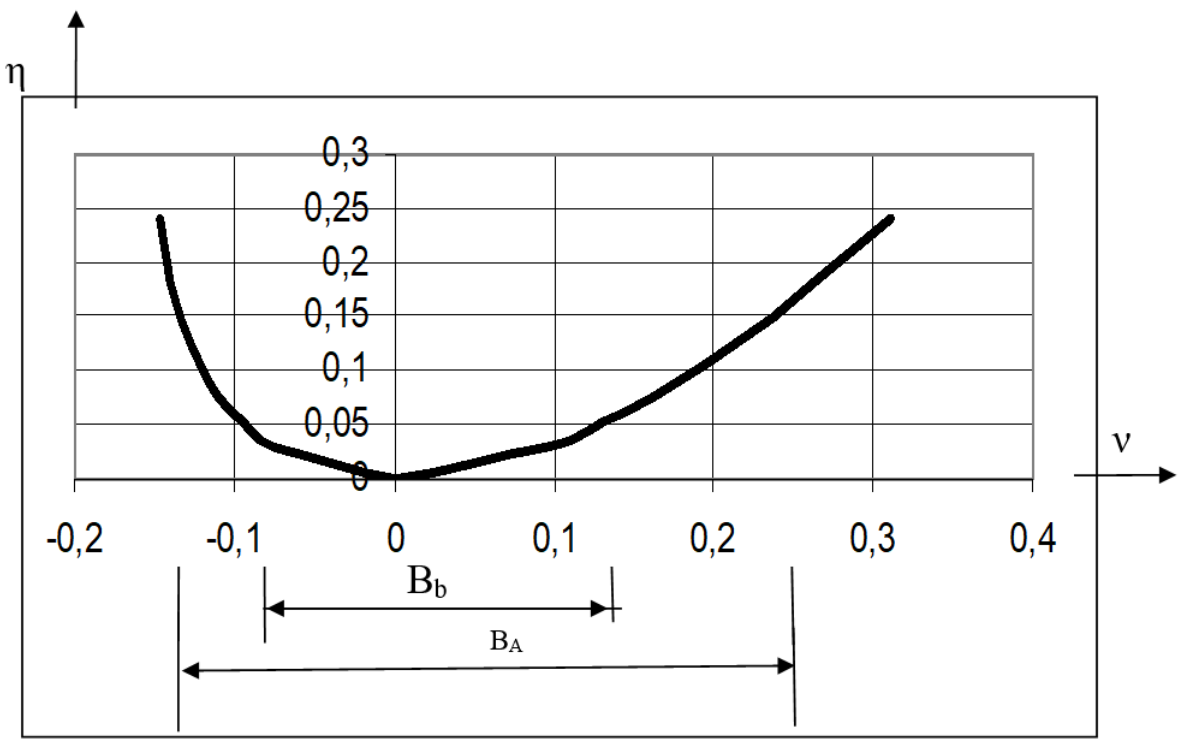

Fig. 3. Spherical disc furrow shape: $\mathrm{Bb}$ - furrow width at field surface level; BA - sowing bandwidth at the level of agricultural requirements.

Seeds in such a furrow will be located at different depths, which contradicts agricultural requirements. For a long time, this circumstance hindered the use of spherical disc coulters. The study of furrow formation, carried out by the authors, showed that, for large-diameter discs at the bottom of the furrow, it is always possible to identify a strip in which the sowing depth has deviations within the agro-tolerance $\mathrm{Aa}= \pm 10 \mathrm{~mm}$. Table 1 shows the values of the width of the furrow $\mathrm{Bb}$ and the width of the sowing strip $\mathrm{Ba}$ for different values of the angles of the disc with a diameter of $660 \mathrm{~mm}$ and a sowing depth of $6 \mathrm{~cm}$. The data show that the width of the sowing strip is less than the width of the furrow by about $20 \%$, but exceeds the strip width of a typical double coulter at row sowing in $10 \ldots 12$ times, reaching at high angles of attack about $200 \mathrm{~mm}$. This means that the spherical disk can provide not row, but real strip sowing.

Table 1. Furrow and sowing strip width $6 \mathrm{~cm}$ sowing depth.

\begin{tabular}{|c|c|c|c|c|c|c|}
\hline Corners & \multicolumn{2}{|c|}{ Tilt angle $\boldsymbol{\beta}=\mathbf{2 0}^{\circ}$} & \multicolumn{2}{c|}{ Tilt angle $\boldsymbol{\beta}=\mathbf{3 0}^{\circ}$} & \multicolumn{2}{c|}{${\text { Tilt angle } \boldsymbol{\beta}=\mathbf{4 0}^{\circ}}^{\circ}$} \\
\hline attacks & Bb. $\mathbf{~ m m}$ & Ba. $\mathbf{~ m m}$ & Bb. $\mathbf{~ m m}$ & Ba. $\mathbf{~ m m}$ & Bb. $\mathbf{~ m m}$ & Ba. $\mathbf{~ m m}$ \\
\hline$\alpha=20^{\circ}$ & 132.8 & 102.7 & 137.7 & 106.6 & 145.3 & 113.7 \\
\hline$\alpha=40^{\circ}$ & 249.6 & 193.7 & 258.9 & 201.5 & 273.2 & 213.7 \\
\hline
\end{tabular}

It is noted that the width of the seeding strip of the spherical disc opener Ba does not depend on the depth of travel, but is determined only by the diameter of the spherical disc and the angles of the installation.

The results obtained form the basis for the development of an innovative spherical disc opener. The spherical disc coulter (Figure 2, b) includes a spherical disc, on the hub of which a metal seed tube with a deflector is attached.

Thus, the problems of furrowing with a spherical disc can in principle be solved by increasing the diameter, controlling the orientation angles and installing a deflector distributor. The advantage of spherical disc is that the stability of work on untreated agrophones remains unchanged.

Solving the problem of furrowing can have a great impact on the design and technological support of strip sowing. Firstly, it unifies the sowing machine with the popular disc harrow and allows you to obtain a compact tillage and sowing complex without high costs. 
Secondly, it revolutionizes sowing technology by combining it with mini and no-till tillage. Subsoil-spread sowing with a spherical disc working body is carried out. This innovation means the birth of a new technology of strip sowing, conventionally called discator technology of strip sowing.

Equipping the seeders with spherical disc coulters with a seed flow distributor opened the way for creating a single-machine compact sowing complex for strip sowing based on a conventional discator. The Absheron Mechanical Plant (AMZ) was a pioneer in the creation of a new technology. Taking the R-4,2A sowing machine as a basis, he modernized the spherical disc working body: equipped the spherical disc openers with a deflector distributor, increased the angle of attack to $30^{\circ}$, which made it possible to increase the sowing strip to $140 \mathrm{~mm}$ with a row spacing of $200 \mathrm{~mm}$. The R-4,2M seeding machine is equipped with such a coulter (Figure 2, b), which makes it possible to carry out a full-fledged strip sowing (Figure 4). Absheron Mechanical Plant produces it under the name "seeding machine" R-4,2M. Its general view is shown in Fig. four.

Spherodisc coulters 9 are installed in two rows rigidly on the beams of the frame 8 . The frame rests on two support wheels 1 and two support-drive rollers 10, and is connected to the tractor with a snitch 3 . On each beam, 16 spherical disks, 9 left and right, are rigidly installed to balance lateral loads (Figure 4). The attack angle is $\alpha=27^{\circ}$, the tilt angle is $\alpha=20^{\circ}$, the sharpening angle is $\delta=25^{\circ}$, and the posterior angle at the level of the bottom of the furrow $\xi=$ $1^{\circ}$. Spherodiscs are mounted on angular contact double-row roller sealed bearings. The lifting of seeds and fertilizers, metered by dispensers 13, up to the seed distributor 6 is carried out by a common bucket elevator 7 . The distribution of the mixture through the seed pipes is carried out by a common distributor of seeds and fertilizers 6 . The seeds, going down the seed tubes 5 , fall into the furrow, cut with a spherical disc to the planting depth; here the seeds are covered with soil of a fine crumbly structure. The cover layer of the soil is rolled by drive 10 and transport tire rollers 11 . This ensures not only good contact with the soil capillaries, but also good reception of atmospheric moisture at the dew point. It is at the dew point that the seeds should be sown. This ensures good drought emergence, sustainable plant development, and good yields.

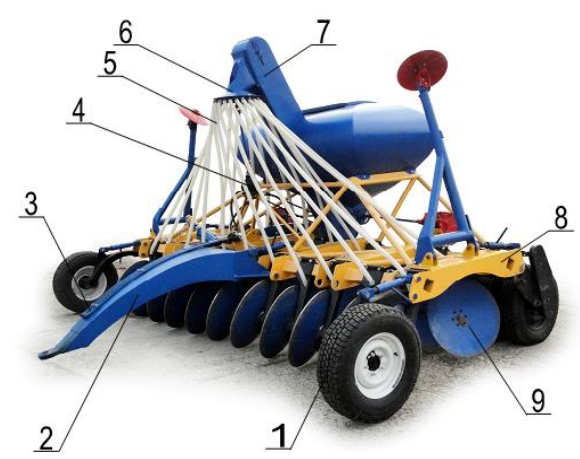

a)

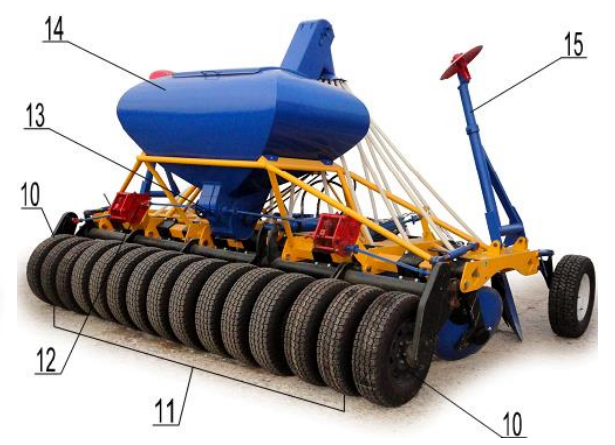

b)

Fig. 4. Seeding machine R-4,2M: a - front view; b - back view: 1 - support wheels; 2 - snitch; 3 hydraulic system; 4 - seed and fertilizer distributor gearbox; 5 - vas deferens; $b$ - seed and fertilizer spreader; 7 - bucket elevator; 8 - frame; 9 - spherical disc coulters, 10 - support-drive rollers; 11 transport tire roller; 12 - seeding rate reducer for seeds and fertilizers; 13 - dispenser; 14 - hopper; 15 - marker.

The technical parameters of the seeders were assessed in accordance with GOST 26025 $[8,9]$ and the proposed normative document. The results of the assessment are listed in Table 2. 
Table 2. Technical characteristics of the seeding machine R-4,2M.

\begin{tabular}{|c|c|c|}
\hline № & Parameter name & Parameter value \\
\hline 1 & Sowing machine model & $\mathrm{R}-4.2 \mathrm{M}$ \\
\hline 2 & Type & semi-mounted \\
\hline 3 & It is aggregated with tractors of class. tf & $1.4 \ldots 3.0$ \\
\hline 4 & Working speed. $\mathrm{km} / \mathrm{h}$ & from 9.0 to 15.0 \\
\hline 5 & Working speed. $\mathrm{km} / \mathrm{h}$ & 4.2 \\
\hline 6 & $\begin{array}{l}\text { Productivity for } 1 \text { hour of main time. ha/h } \\
\text { (calculated) }\end{array}$ & 4.0 to 8 \\
\hline 7 & Sowing machine weight. kg. not more & $3680 \pm 5 \%$ \\
\hline 8 & Seed hopper capacity. l. not less & 1000 \\
\hline 9 & Capacity of the fertilizer bunker. 1. not less & 600 \\
\hline 10 & $\begin{array}{l}\text { Overall dimensions (length* width*height). } \mathrm{mm} \\
\text { in working position (excluding markers). } \\
\text { in transport position (including markers) }\end{array}$ & $\begin{array}{l}4300 * 4900 * 2550 \\
4940 * 2600 * 2750\end{array}$ \\
\hline 11 & Main row spacing. $\mathrm{mm}$ & $202 \pm 15$ \\
\hline 12 & Coulter type & spherical disc \\
\hline 13 & Spherical disc diameter. $\mathrm{mm}$ & 660 \\
\hline 14 & Disc attack angle. deg. & 27 \\
\hline 15 & Disc inclination angle. degrees. & 20 \\
\hline 16 & Diffuser type & deflector \\
\hline 17 & Sieving strip width. $\mathrm{mm}$ & $50 \ldots 130$ \\
\hline 18 & Limits of stroke depth control. mm & from 30 to 80 \\
\hline 19 & Number of seeding devices. pcs & to 32 \\
\hline 20 & Seeding rate for grain seeds. $\mathrm{kg} / \mathrm{ha}$ & $1.6 \ldots 306$ \\
\hline 21 & Seeding rate for fertilizers. $\mathrm{kg} / \mathrm{ha}$ & $(30 \ldots 98) \pm 10$ \\
\hline 23 & $\begin{array}{l}\text { Deviation of the seeding rate from the } \\
\text { specified. } \%\end{array}$ & 10 \\
\hline 24 & Number of attendants. people & 1 \\
\hline 25 & Labor intensity of aggregation. man-h. no more & 0.1 \\
\hline 26 & $\begin{array}{l}\text { The duration of the transfer of the machine } \\
\text { from the working position to the transport } \\
\text { position and vice versa. h. no more }\end{array}$ & 0.75 \\
\hline 27 & $\begin{array}{l}\text { Reliability factor of the technological process. } \\
\text { not less }\end{array}$ & 0.98 \\
\hline 28 & Installed trouble-free operating time. $\mathrm{h}$ & 35 \\
\hline 29 & Service life. years & under 8 \\
\hline 30 & Warranty period of operation. months & 12 \\
\hline 31 & $\begin{array}{l}\text { Availability factor taking into account: } \\
\text { - operational time } \\
\text { - organizational time }\end{array}$ & $\begin{array}{l}0.98 \\
0.97\end{array}$ \\
\hline
\end{tabular}

\section{Discussion}

Equipping seeders with spherical disc coulters with a decent seed flow distributor will open the way for creating a single-machine compact sowing system for strip sowing based on a conventional discator. The developed sowing machine $\mathrm{R}-4,2 \mathrm{M}$ with spherical disc coulters is capable of performing several agrotechnical operations simultaneously:

- pre-sowing cultivation with weed control;

- raising the bed without disturbing the capillary layer of the seed bed;

- sowing seeds to a depth of $30-80 \mathrm{~mm}$ on the seedbed without disturbing the capillary moisture layer, providing plants with irrigation moisture,

- providing plants with a biologically expedient and rational nutritional area; 
- application of mineral fertilizers and biological products to the soil;

- Creation of a finely lumpy mulch layer above the seed bed, ensuring the most favorable dew point at a depth of $5 \mathrm{~cm}$.

- rolling crops;

- leveling the soil surface.

Additional functions were implemented: introduction of liquid humus biological products into the soil; creating a mulch layer over the seedbed.

A positive feature of the new technology is the possibility of placing seeds on a dense bed, covering them with the soil of the treated layer and creating a tight contact of the seeds with the soil due to rolling. At the same time, for the development of the root system in the initial period, the underlying soil layer does not have overconsolidation of more than 1.3 $\mathrm{g} / \mathrm{cm}^{3}$.

The machine is capable of working on all crop production technologies:

- according to the classic (as a seeding machine, cultivator, discator);

- by min-till (as a discator, cultivator, seeding machine);

- on no-till - as a direct seeding machine;

- by strip-till - as a tillage and sowing tool.

- continuous or strip sowing of cereals.

The seeding machine is capable of sowing binary crops with the introduction of both liquid and granular fertilizers and biological products.

Field studies of discator strip sowing technology have been carried out for the last 5 years. In 2016 - 2017, tests of the R-4.2M + MTZ-82 complex were carried out at the test site of the Novokuban branch of the Federal State Budgetary Scientific Institution "Rosinformagrotech" when sowing winter wheat according to its predecessor - corn for grain [3, 10-15]. The work of the seeder was studied when sowing winter wheat on zero agricultural grounds with different predecessors: wheat, corn, sunflower with residual stubble and stalk residues.

Observations have shown that a disc sowing machine with spherical disc coulters is distinguished by the reliability of soil preparation in a wide range of agrophone conditions and moisture. The new technology does not require preliminary preparation for sowing, even after coarse-stemmed predecessors. A large mulching effect is noted, which can delay the dehydration of the seed layer.

The established agrotechnical assessment of the quality of the seeder was carried out in accordance with the standards of STO AIST 4 2-2004, STO AIST 5 12006, OST 103.2-2002. The standards were adapted to drill sowing and did not provide for monitoring the supply of seeds with feeding areas. Therefore, in addition to the standard method, the monitoring of the supply of seeds with feeding areas was carried out: the width of the spread was measured and the proportion of seeds provided with feeding areas was calculated. A new indicator of the provision of seeds with a nutritional area was applied. As an indicator, the relative number (proportion) of seeds $\lambda$, provided with a sufficient nutritional area from all sown

$$
\lambda=\mathrm{nfa} / \mathrm{N},
$$

where nfa - the number of seeds provided with a feeding area of $10 \mathrm{~cm}^{2}$ out of the total number $\mathrm{N}$.

To assess the uniformity of the indicator along the length of the run, it is divided into sections with a length of $1 \mathrm{~m}$; determine the proportion of seed supply in the $\mathrm{i}$-th section $\lambda \mathrm{i}$, $\mathrm{i}=1 \ldots \mathrm{n}$ Traditional statisticians are used for assessments: the average $\lambda$ av, standard deviation $\Delta \lambda$ and the coefficient of variation $v$.

The advantage of indicator (2) is simplicity and objectivity. The norm does not contradict OST-10.5.1-2000, it is based on the same principle of obtaining statistical indicators.

It turned out that strip sowing provides a share of availability up to $85 \%$ with a spreading width of up to $140 \mathrm{~mm}$, and about $20 \%$ for a seeder with a standard double disc opener. 
The results of studies carried out in the fields of the Rostov region in 2018 showed that when sowing winter wheat with the proposed seeder, the seeds germinate more amicably and 2-3 days earlier than winter wheat sown with a serial seeder, the plants develop better (Figure $5)$.

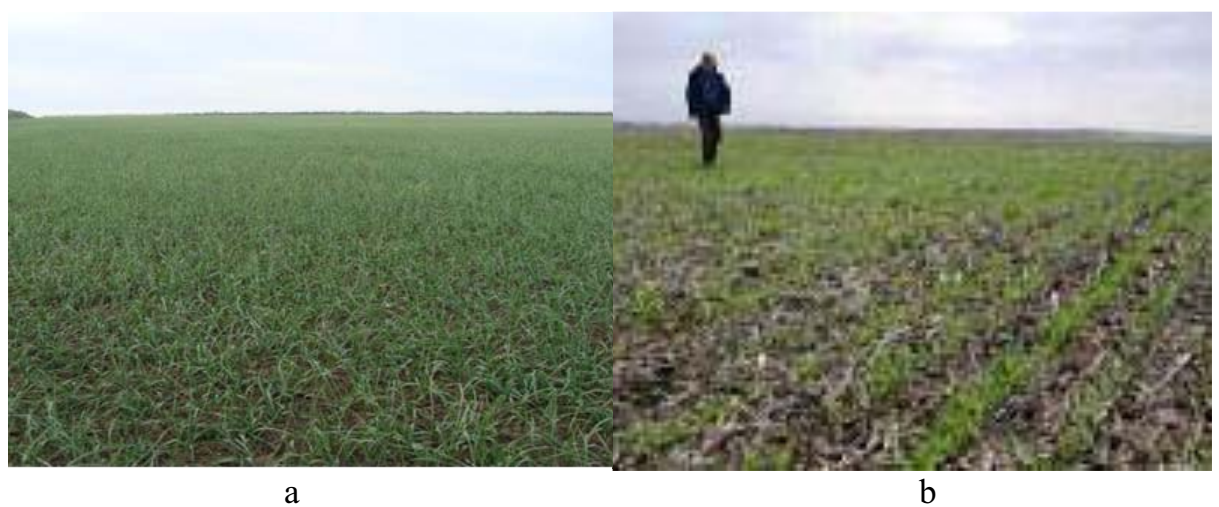

Fig. 5. Photo, shoots of winter wheat, sown after sunflower: $a$ - sown RA-4,2M by strip method; b row-sown.

But the main thing is that strip sowing led to a significant increase in yield, which was steadily observed in the process of many years of testing machines with a spherical disc opener.

The yield of wheat sown with the proposed no-till planter in arid conditions in 2016 turned out to be $50 \%$ higher compared to the yield of this crop in the control plots and, accordingly, averaged about $80 \mathrm{c} /$ ha (when sowing with a serial seeder $-40 \mathrm{c} / \mathrm{ha}$.

The collection of information on the achieved yield in the fields of farms using discator technologies of strip sowing with the R-4,2M machine has been carried out. The yield was assessed directly at the final phase of the grain harvest. A survey of farms showed that it provides a real increase in yield up to $70-90 \mathrm{c} / \mathrm{ha}$, depending on the predecessor and natural conditions.

This can be explained by the fact that strip sowing increases the used area of the field, it becomes possible to place a larger number of plants on the field. Providing them with the necessary nutritional areas causes more intensive vegetation and ear fat of each plant.

The identification of all the mechanisms of the influence of strip sowing on the cultivation of cereals has yet to be identified by biologists. But the very fact of a significant increase in yield exists.

An even more significant increase in yield was obtained with the use of humus supplements in moisture-free years 2019 and 2018. In some farms in the South of Russia, wheat yield after wheat was obtained at the level of $115 \mathrm{c} / \mathrm{ha}$, and after corn up to $130 \mathrm{c} / \mathrm{ha}$. Seedlings and harvests are guaranteed even in drought conditions due to the mulching of the field surface with crop residues. The seeder operates using a simple "sow and harvest" technology and allows you to get rid of $90 \%$ of the classic costs without the use of chemicals, consuming no more than $41 /$ ha of diesel fuel.

The calculation results showed that the use of discator technology for strip sowing with the R-4.2 complex, in comparison with the traditionally used one, leads to a decrease (per 1000 ha): the need for equipment - by $63 \%$; the need for machine operators - by $43 \%$; in motor fuel - by $63 \%$; in capital expenditures - by $49 \%$. 


\section{Output}

The problem of mechanization of strip sowing, which increases the area of seed feeding, can technically be successfully solved on the basis of discator technology, which makes it possible to create compact single-machine seeding complexes that can have a positive effect on the technical and economic indicators and technology of grain cultivation. The advantage of the discator strip sowing technology is a significant increase in yield due to better use of the field area and the provision of seeds with nutritional areas.

\section{Acknowledgements}

The work was carried out within the framework of proactive research.

\section{References}

1. A.K. Eroplanov, Seeder-cultivator. Description of the invention to the patent ru 2680 954(13)c1 7, 34-49 (2019)

2. Yu.A. Tsarev, A.K. Ererlanov, E.Yu. Adamchukova, Machinery and equipment for the village 3(249), 48-50 (2018)

3. M.G. Chaplygin, D.A. Petukhov, S.A. Sviridova, Machinery and equipment for the village 9 (2017)

4. Multifunctional alagriculture and rural development, regional specificities : international scientific meeting (Belgrad, 2010)

5. O.E. Patseka, S.I. Novoseletsky, I.S. Sysenko, Enthusiasts of agrarian science a collection of articles based on the materials of the international conference dedicated to the soviet and Russian organizer of agriculture, academician of the vashnil and ras, hero of socialist labor (2016)

6. M.A. Mazirov, N.S. Matyuk, V.D. Polin, Modern trends in the scientific support of the agro-industrial complex of the upper volga region collective monograph: in 2 volumes (Federal state budgetary scientific institution "Verkhnevolzhsky agrarian scientific center", Ivanovo, 2018)

7. D.G. Polyakov, A.V. Khalin, F.G. Bakirov et al., Bulletin of the orenburg scientific center of the ural branch of the russian academy of sciences 4, 13 (2016)

8. S.A. Tulkubaeva, V.G. Vasin, New technologies 1, 104-112 (2017)

9. V.G. Vasin, S.A. Tulkubaeva, A.B. Abuova, Cultivation of spring rapeseed with direct sowing in the conditions of northern Kazakhstan. The collection: innovative achievements of science and technology of the agro-industrial complex collection of scientific papers of the international scientific and practical conference (2017)

10. E.Yu. Dolgov, Cultivation of sunflower in the chernozem zone of the Volgograd region with direct sowing. The collection: ecological aspects of land use in modern economic formations materials of the international scientific and practical conference (2017)

11. A.V. Davidenko, V.G. Shol, Yu.N. Shol, The influence of cultivation technology on the productivity of winter wheat during direct sowing in the central zone of the Krasnodar territory. The collection: bulletin of scientific and technical creativity of youth of the Kuban state agrarian university in 4 volumes (2016)

12. N.A. Nazarov, S. Murchenko, Productivity of sunflower during dump tillage and direct sowing. The collection: bulletin of scientific and technical creativity of youth of the Kuban state agrarian university in 4 volumes (2016) 
13. A.V. Pozdnyakova, M. Tagirov, A.A. Veles, Influence of cultivation technology on the productivity of winter wheat under direct sowing in the central zone of the Krasnodar territory 7-1(61), 59-64 (2018)

14. A.A. Zavalin, V.K. Dridiger, V.P. Belobrov, S.A. Yudin, Soil science 12, 1506-1516 (2018)

15. R.V. Gromov, V.V. Golubev, Analiz konstruktsii ploshnikov seeders for direct seeding. The collection: combined crops of field crops in the crop rotation of the agrolandscape international scientific ecological conference (2016)

16. V.V. Kurushin, Development of a seeder for sowing grain crops with justification of its design parameters and operating modes. Abstract of the dissertation for the degree of candidate of technical sciences (Ufa, 2018) 